\title{
PENGARUH PENGUMUMAN CEO BAKAL WAKIL PRESIDEN SEBELUM DAN SETELAH HASIL PILPRES TERHADAP RETURN SAHAM DI BEI
}

\author{
Fitriaty $^{1)}$, Muhammad Haris Saputra ${ }^{2)}$ \\ ${ }^{1,2)}$ Fakultas Ekonomi dan Bisnis, Universitas Jambi \\ Email: ${ }^{13}$ fitriyaty@unja.ac.id ${ }^{2)}$ mharissaputra97@gmail.com
}

\begin{abstract}
Abstrak
Harga saham terpengaruh dengan semua jenis informasi, baik informasi masa lalu, informasi publik, maupun informasi privat. Informasi tersebut dapat berupa laporan tahunan perusahaan, pembagian dividen, pemecahan saham, pengumuman merger dan akuisisi, analisis dari para analis saham. Salah satu informasi publik yang dapat diketahui investor melalui berbagai media adalah pengumuman tentang Chief Executife Officer (CEO). Penelitian ini bertujuan untuk melihat pengaruh pengumuman CEO yang menjadi bakal calon wakil presiden indonesia terhadap return saham dan Pengaruh Pengumuman Hasil Pemilihan Presiden Indonesia terhadap Return Saham yang dimiliki oleh bakal calon wakil presiden di Bursa Efek Indonesia. Metode pengukuran menggunakan abnormal return, kemudian di rata ratakan menjadi Average Abnormal Return dan dihitung Comulatif harian Average Abnormal Return langkah selanjutnya adalah diinterpretasikan. Hasil dari penelitian ini Average Abnormal return bakal calon rata rata memiliki nilai positif dan Setelah pengumumn Pilpres juga rata rata memiliki nilai Positif, sedangkan untuk nilai Comulatif Average Abnormal Return bakal calon lebih besar dari Comulatif Average Abnormal Return setelah pengumuman Pilpres artinya pemilu memiliki dampak terhadap terhadap return saham.
\end{abstract}

Kata Kuci : CEO, Wakil Presiden, Return, Saham, BEI

\begin{abstract}
Stock prices are affected by all kinds of information, both past information, public information, and private information. The information can be in the form of company annual reports, dividend distributions, stock splits, announcements of mergers and acquisitions, analysis from stock analysts. One of the public information that can be known by investors through various media is the announcement of the Chief Executive Officer (CEO). This study aims to see the effect of the announcement of the CEO who is the candidate for vice president of Indonesia on stock returns and the effect of the announcement of the results of the Indonesian presidential election on the return of shares owned by the candidate for vice president on the Indonesia Stock Exchange. The measurement method uses abnormal returns, then averaged to become Average Abnormal Return and calculated daily cumulative Average Abnormal Return, the next step is to be interpreted. The results of this study mean that the average abnormal return for candidates has a positive value and after the announcement of the presidential election, the average average abnormal return for candidates is greater than the cumulative average abnormal return after the announcement of the presidential election, meaning that the election has an impact on the stock returns.
\end{abstract}

Keywords : CEO, Vice President, Return, Stocks, IDX 


\section{PENDAHULUAN}

Pasar modal pada dasarnya sama seperti pasar pada umumnya, yaitu tempat bertemunya penjual dan pembeli. Di pasar modal, yang paling umum diperjual belikan adalah modal berupa hak pemilikan perusahaan (saham) dan surat pernyataan hutang perusahaan (obligasi). Di pasar modal Indonesia, yang paling banyak diperdagangkan adalah saham. Agar para investor bersedia untuk menyalurkan dananya melalui pasar modal, para investor menginginkan perasaan aman akan investasinya(Jogiyanto,2017) Maka, para investor berusaha mendapatkan berbagai jenis informasi yang berguna dan melakukan berbagai teknik analisis untuk mengurangi ketidakpastian investasi, memperkirakan aliran kasnya di masa yang akan datang, menentukan sekuritas apa yang harus dibeli dan dijual dan tentunya menghasilkan return yang tinggi.

Pengambilan informasi yang relevan sebagai pertimbangan untuk mengambil keputusan dalam melakukan investasi di pasar modal sangat diperlukan oleh seorang investor (Bahtera; 2017). Informasi tersebut dibutuhkan untuk menetapkan harga saham sehingga mencerminkan hubungan antara tingkat risiko sebagai konsekuensi yang mungkin harus dihadapi atau keuntungan yang akan diperoleh sebagai imbalan atas investasi yang telah dilakukan, dan bagi para investor untuk memperoleh portofolio sebagai preferensinya sendiri dalam mendapatkan tingkat pengembalian maksimum dengan tingkat risiko tertentu. Harga saham terpengaruh dengan semua jenis informasi, baik informasi masa lalu, informasi publik, maupun informasi privat. Informasi tersebut dapat berupa laporan tahunan perusahaan, pembagian dividen, pemecahan saham, pengumuman merger dan akuisisi, analisis dari para analis saham, dan masih banyak lagi (Bahtera;2017). Salah satu informasi publik yang dapat diketahui investor melalui berbagai media adalah pengumuman tentang Chief Executife Officer (CEO).

Chief Executive Officer atau sering juga disebut manajer puncak atau direktur utama atau merupakan eksekutif tertinggi yang mengelola keseluruhan organisasi. CEO bertugas untuk mencapai tujuan organisasi, strategi keseluruhan, dan kebijakan operasional (Warner et al. 1988). CEO juga memiliki tanggung jawab untuk membuat keputusan mengenai berbagai aktivitas seperti akuisisi perusahaan lain, investasi dalam penelitian dan pengembangan, memasuki atau mengabaikan berbagai pasar, dan membangun fasilitas pabrik dan kantor yang baru (Griffin, 2004).

Diniar Ayudia Hanung \& Kiryanto,(2015) Analisis Dampak Pemilu Presiden Jokowi terhadap Return Saham, Pemilihan presiden tanggal 9 Juli 2014 memberikan perubahan terhadap abnormal return saham dan TVA yang signifikan pada 5 hari sebelum dan sesudah pemilu. Sesudah pemilihan presiden abnormal return saham lebih rendah dibanding sebelum pemilihan presiden Jika dilihat berdasarkan reaksi per hari dari investor selama 5 hari sebelum hingga 5 hari sesudah pemilu pilpres, diperoleh reaksi yang signifikan terjadi pada 4 dan 2 hari sebelum pemilihan presiden yang merupakan reaksi positif dari investor.

Lia Nur Islami \& Endi Sarwoko,(2012) Reaksi Pasar Modal Indonesia Terhadap Pergantian Menteri Keuangan didapatkan Hasil bahwa terdapat signifikansi abnormal return dan nilai TVA pada saat pengumuman peristiwa dan hari di sekitar pengumuman peristiwa. Sehingga dapat disimpulkan bahwa pasar modal Indonesia bereaksi atas peristiwa kemunduran Sri Mulyani dari jabatan menteri keuangan. Nunung Nurhaeni,(2009) Pengaruh Pemilihan Umum terhadap return saham terdapat perbedaan rata-rata abnormal return yang signifikan sebelum dan setelah pemilu legislatif 2009, Berdasarkan uji statistik terhadap rata-rata abnormal return saham selama periode peristiwa, ditemukan bahwa terdapat perbedaan rata-rata abnormal return dan nilai TVA 
yang signifikan sebelum dan setelah perisitiwa pemilu legislatif. Lamasigi, (2002) Reaksi saham di BEJ Terhadap Pergantian Presiden Republik Indonesia mendapatkan hasil Tidak terdapat perbedaan abnormal return sebelum dan sesudah Peristiwa dilihat dari perhitungan abnormal return.

Ni Wayan Kustami dan Bradi Rikumahu, (2015) Pengaruh Chief Executive Officer Turnover Effect on Stock Company Return That Was Inside Index LQ45 Periode 20072012 Pasar tidak bereaksi terhadap pengumuman pergantian CEO dilihat dari Abnormal Retun Sebelum dan sesudah terjadinya peristiwa mendapatkan hasil yang negatif. Nindita Yoanna Desiantari (2009) Reaksi pasar terhadap pengumuman pergantian ceo diukur dengan variabilitas return saham hasil penelitian ini menemukan bahwa pasar tidak bereaksi terhadap seluruh pengumuman pergantian CEO. Novyandri Taufik Bahterayang(2017) menyatakan bahwa investor Indonesia menyukai pergantian yang sesuai, yakni pergantian secara rutin dengan CEO pengganti berasal dari dalam dan investor bereaksi negatif apabila proses pergantian adalah rutin outside.

Berdasarkan penelitian-penelitian yang telah dilakukan sebelumnya, banyak peneliti yang meneliti mengenai pengaruh Pengumuman pergantian CEO pada pasar modal di berbagai negara dan juga pasar bereaksi terhadap pergantian CEO. Hal ini memotivasi penulis untuk melakukan penelitian dengan menggabungkan tentang pengaruh CEO dan juga politik terhadap return saham. Menurut Samsul (2006: 200), faktor-faktor yang mempengaruhi return saham terdiri atas faktor makro dan faktor mikro.dimana didalamnya ada juga kondisi Politik. Peristiwa-pristiwa politik merupakan salah satu reesiko non-ekonomi yang dapat berpengaruh pada keputusan investor dalam beinvestasi dipasar modal, karena situasi politik suatu Negara pada dasarnya berpengaruh pada kondisi perekonomian negara tersebut (Katti:2018). peristiwa Pemilihan presiden ini sangat layak untuk dilakukan penelitian karna peristiwa ini terjadi setiap 5 tahun sekali, dan pada pemilihan presiden tahun 2019 ini berbeda dengan pemilihan sebelumnya karna salah satu kandidat merupakan pendiri perusahaan atau CEO yang perusahaanya terdaftar di Bursa Efek Indonesia.perusahaan yang dimiliki oleh CEO bakal calon yag akan dijadikan objek penelitian adalah: SRTG (Saratoga Investama), TBIG (Tower Bersama Indonesia), MPMX( Mitra Phinastika Mustika), ADRO (Adaro Energy), NRCA (Nusa Raya Cipta), PALM( Provident Agro)

\section{METODE PENELITIAN}

Teknik analisis data yang digunakan untuk menganalisis reaksi pasar disekitar pengumuman CEO dalam penelitian ini dilakukan dengan mengikuti prosedur metodologi penelitian studi peristiwa Tandelilin (2010:572), dengan prosedur sebagai berikut:

Mengidentifikasi tanggal pengumuman CEO menjadi bakal calon wakil presiden, dan pengumuman hasil presiden tanggal tersebut dijadikan sebagai event date. Event date adalah hari terjadinya peristiwa atau hari ke nol ( $\mathrm{t} 0$ ).

Menentukan rentang waktu studi peristiwa. Studi peristiwa menyelidiki respons pasar terhadap kandungan informasi dari suatu pengumuman atau publikasi peristiwa tertentu. Tandelilin (2012:571) .

Menghitung return aktual masing-masing sampel selama periode pengamatan. Langkah-langkah pengujian yang dilakukan adalah menghitung abnormal return di sekitar periode peristiwa untuk mengetahui adanya reaksi pasar atas pengumuman CEO bakal calon dan hasil Pilpres tahun 2019 berdasarkan metode yang telah ditetapkan.

Rit $=\frac{\left(P_{i t}-P_{i t-1}\right)}{P_{i t-1}}$ 


\section{Keterangan}

Rit: Actual return realism saham I pada waktu $\mathrm{t}$

Pit: Harga Saham i pada waktu t

Pit-1: Harga saham i pada waktu t-1

Menentukan metode yang akan digunakan. Teknik yang digunakan untuk mengestimasi expected return dalam studi peristiwa ini adalah market-adjusted model. Menurut Hartono (2009:568), model sesuaian pasar (market-adjusted model) menganggap bahwa penduga yang terbaik untuk mengestimasi return suatu sekuritas adalah return indeks pasar pada saat tersebut. Dengan menggunakan model ini, maka tidak perlu menggunakan periode estimasi untuk membentuk model estimasi, karena return sekuritas yang diestimasi adalah sama dengan return indeks pasar.

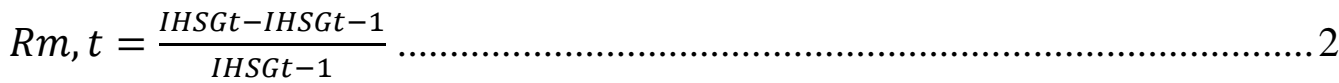

Keterangan

Rm,t: Return pasar waktu $\mathrm{t}$

IHSGt: Nilai IHSG pada waktu $t$

IHSGt-1: Nilai IHSF pada saat t-1

Karna menggunakan expected return market adjusted model maka rumusnya:

$E($ Rit $)=R m, t$ 3

Keterangan

Rm,t: Return pasar waktu $\mathrm{t}$

$\mathrm{E}(\mathrm{Rit})$ : Expected return untuk saham i pada hari ke $\mathrm{t}$

Menghitung abnormal return tiap-tiap saham selama event period.

ARit $=$ Rit $-E($ Rit $)$ 4

Keterangan

ARit: Abnormal return untuk saham i pada hari ke $\mathrm{t}$

Rit : Actual return realism saham I pada waktu $\mathrm{t}$

$\mathrm{E}(\mathrm{Rit})$ : Expected return untuk saham i pada hari ke $\mathrm{t}$

Menghitung Average Abnormal Return (AAR) yang merupakan rata-rata abnormal return (AR) dari semua jenis saham yang sedang dianalisis secara harian.

$A A R t=\frac{\sum_{i=1}^{k} A R i t}{k}$

keterangan

AARt: AAR pada hari ke $\mathrm{t}$

ARit: Abnormal return untuk saham i pada hari ke $\mathrm{t}$

$\mathrm{K}$ : jumlah sekuritas yang terpengaruh oleh pengumuman peristiwa

Menghitung Cumulative Average Abnormal Return (CAAR) yang merupakan kumulatif harian AAR mulai dari hari pertama sampai dengan hari-hari berikutnya .

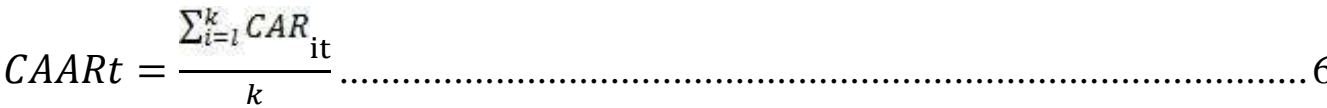
6

Keterangan

CAAR: Cumulative average abnormal return pada hari ke $\mathrm{t}$

CAR: Cumulative abnormal return pada hari ke $\mathrm{t}$

$\mathrm{K}$ : Jumlah sekuritas yang terlibat 


\section{HASIL DAN PEMBAHASAN}

Tabel 1. Abnormal Return Pengumuman CEO Menjadi Bakal Calon Wakil Presiden

\begin{tabular}{|c|c|c|c|c|c|c|c|c|c|c|c|c|}
\hline \multirow{2}{*}{$\mathrm{N}_{0}$} & \multirow{2}{*}{ Kode Emiten } & \multicolumn{11}{|c|}{ Abnormal Return Harian (Ari) } \\
\hline & & $t .5$ & $t-4$ & $t-3$ & $t-2$ & $\mathrm{t}-\mathrm{l}$ & to & $\mathrm{t}+1$ & $t+2$ & $t+3$ & $\mathrm{t}+4$ & $\mathrm{t}+5$ \\
\hline 1 & NRCA & $-0,0169$ & 0,0007 & $-0,0156$ & 0,0016 & $-0,0006$ & 0,0206 & 0,0083 & 0,0253 & $-0,0050$ & $-0,0081$ & 0,0320 \\
\hline 2 & TBIG & 0,0652 & 0,0096 & $-0,0421$ & 0,0107 & 0,0400 & $-0,0081$ & 0,0024 & 0,0312 & 0,0200 & $-0,0125$ & $-0,0295$ \\
\hline 3 & SRTG & 0,0381 & 0,0007 & $-0,0156$ & $-0,0368$ & $-0,0193$ & 0,0130 & 0,0196 & 0,0461 & 0,0104 & $-0,0580$ & 0,0056 \\
\hline 4 & PALII & 0,0468 & 0,0007 & $-0,0776$ & 0,0310 & $-0,0006$ & $-0,0023$ & $-0,0092$ & 0,0138 & 0,0971 & 0,0261 & 0,1447 \\
\hline 5 & ADRO & $-0,0191$ & 0,0033 & $-0,0053$ & 0,0118 & 0,0045 & $-0,0228$ & $-0,0149$ & $-0,0064$ & $-0,0008$ & 0,0225 & $-0,0348$ \\
\hline 6 & MPIIX & 0,0327 & $-0,0418$ & $-0,0304$ & $-0,0084$ & 0,0196 & $-0,0100$ & $-0,0020$ & 0,0054 & $-0,0155$ & 0,0026 & 0,0003 \\
\hline
\end{tabular}

Sumber: Hasil verhithnean vemulis

Abnormal return dapat terjadi karena adanya kejadian-kejadian tertentu , misalnya hari libur nasional, awal bulan, suasan politi yang tidak menentu, kejadian yang luar biasa, stock split, penawaran perdana saham dan lain-lain(Jogiyanto, 2000). Dari table 1 diatas dapat dilihat disaat pencalonan perusahaan yang memiliki nilai abnormal return terendah yaitu ADRO dengan nilai -0,0228 dan tertinggi adalah NRCA dengan 0,026. Jika dilihat di hari pengumuman bakal calon dibandingkan dengan sebelum dan setelah nilai abnormal return berfluktuatif ini disebabkan informasi yang diperolah oleh investor, membuat para investor untuk menahan dan menjual saham yang dia punya untuk menghindari resiko. Kenaikan nilai abnormal return disaat pencalonan tidak berjalan lama karna investor bereaksi disaat pengumuman pencalonan saja. hasil ini berbeda dengan penelitian yang dilakukan Diniar dan Kiryanti; 2015 yang mendapatkan hasil abnormal return bernilai negative disaat sebelum pilpres.

Tabel 2. Abrormeal Retwon Setelah Pengumuman Hasil Pemilhan Presiden

\begin{tabular}{|c|c|c|c|c|c|c|c|c|c|c|c|c|}
\hline \multirow{2}{*}{$\mathrm{N}_{0}$} & \multirow{2}{*}{$\begin{array}{l}\text { Kode } \\
\text { Emiten }\end{array}$} & \multicolumn{11}{|c|}{ Abnornal Return Harian (Ari) } \\
\hline & & $t-5$ & $t-4$ & $t-3$ & $t-2$ & $t-1$ & t0 & $t+1$ & $t+2$ & $t+3$ & $\mathrm{t}+4$ & $t+5$ \\
\hline 1 & SRTG & 0,003 & 0,004 & 0,017 & 0,006 & 0,029 & $-0,038$ & 0,002 & $-0,016$ & $-0,004$ & $-0,010$ & 0,011 \\
\hline 2 & ADRO & 0,015 & 0,015 & $-0,046$ & 0,025 & $-0,014$ & 0,044 & 0,002 & 0,021 & $-0,020$ & $-0,007$ & 0,015 \\
\hline 3 & MPMX & 0,006 & 0,011 & 0,014 & 0,020 & $-0,006$ & 0,013 & 0,014 & 0,036 & 0,007 & 0,004 & 0,033 \\
\hline 4 & TBIG & $-0,081$ & $-0,016$ & $-0,021$ & 0,012 & 0,003 & $-0,004$ & 0,031 & 0,000 & 0,008 & 0,005 & 0,017 \\
\hline 5 & NRCA & $-0,081$ & $-0,006$ & $-0,013$ & 0,023 & $-0,025$ & 0,009 & 0,002 & 0,012 & $-0,015$ & 0,015 & 0,006 \\
\hline 6 & PAIMI & 0,010 & 0,015 & 0,014 & $-0,028$ & $-0,014$ & 0,076 & 0,002 & 0,000 & $-0,027$ & 0,094 & $-0,060$ \\
\hline
\end{tabular}

Dari tabel 2 dapat dilihat nilai return saham perusahaaan CEO disaat pengumuman hasil Pilpres yang memiliki nilai Return terendah yaitu perusahaan SRTG memiliki nilai 0,0383 dan yang nilai tinggi yaitu perusahaan PALM dengan nilai return 0,0758. Disaat pengumuman hasil Pilpres oleh KPU abnormal return saham perusahaan yang dimiliki oleh Cawapres ini mengalami kenaikan dimana para Investor lebih tertarik untuk menjual sahamnya karna hasil Pilpres menyatakan bahwa pemilik perusahaan ini kalah dalam Pilpres, untuk itu investor lebih tertarik menjual saham yang dia miliki agar terhindar dari resiko yang tidak diinginkan, karna Investor berharap Pemilik perusahaan ini menang di Pilpres agar bisa memberikan citra dan kepastian untuk perusahaan yang dimiliki oleh Cawapres. 
Tabel 3. AAR dan CAAR Pengumuman CEO Menjadi Bakal Calon Wakil presiden

\begin{tabular}{lccc} 
Hari & $\mathrm{t}$ & $\begin{array}{c}\text { AAR(Average } \\
\text { Abnormal Return) }\end{array}$ & $\begin{array}{c}\text { CAAR(Comulative } \\
\text { Average Abnomal } \\
\text { Return) }\end{array}$ \\
\hline 02 Agustus 2018 & $\mathrm{t}-5$ & 0,0245 & 0,019993018 \\
03 Agustus 2018 & $\mathrm{t}-4$ & $-0,0045$ & $-0,0111$ \\
06 Agustus 2018 & $\mathrm{t}-3$ & $-0,0311$ & $-0,0094$ \\
07 Agustus 2018 & $\mathrm{t}-2$ & 0,0017 & $-0,0022$ \\
08 Agustus 2018 & $\mathrm{t}-1$ & 0,0073 & $-0,0038$ \\
09 Agustus 2010 & $\mathrm{to}$ & $-0,0016$ & $-0,0031$ \\
10 Agustus 2018 & $\mathrm{t}+1$ & 0,0007 & 0,0162 \\
13 Agustus 2018 & $\mathrm{t}+2$ & 0,0192 & 0,0339 \\
14 Agustus 2018 & $\mathrm{t}+3$ & 0,0177 & 0,0293 \\
15 Agustus 2018 & $\mathrm{t}+4$ & $-0,0046$ & 0,0490 \\
16 Agustus 2018 & $\mathrm{t}+5$ & 0,0197 &
\end{tabular}

Dari table 3 dapat dilihat nilai Average abnormal return (AAR) menunjukan reaksi paling kuat, baik positif maupun negatif, dari keseluruhan jenis saham pada hari-hari tertentu selama window periode (Samsul, 2006: 277). Berdasarkan Tabel 3 dapat dilihat average abnormal return periode pengumuman CEO menjadi bakal calon wakil presiden Indonesia rata rata hasil perhitungan AAR memiliki nilai positif, nilai terendah itu terjadi pada t-3 yaitu $-0,0311$ dan nilai AAR tertinggi terjadi pada t-5 yaitu 0,0245 . AAR juga rata rata bernilai positif artinya return dari perusahaan memiliki nilai bagus.

Dari tabel 3 juga dapat dilihat nilai dapat dilihat bahwa CAAR menghasilkan nilai yang positif, mengidentifikasikan bahwa investor cendrung bereaksi positif terhadap pengumunan CEO menjadi bakal calon wakil presiden Indonesia, nilai CAAR terendah terjadi pada $\mathrm{t}-3-0,0111$ dan nilai tertinggi terjadi pada $\mathrm{t}+5$ dengan nilai 0,0490 . Perhitungan Cumulative Average Abnormal Return (CAAR) diperoleh dengan mengakumulasikan AAR pada hari ke-t, yaitu mulai hari t-5 sampai dengan $t+5$.

\begin{tabular}{|c|c|c|c|}
\hline Hari & $t$ & $\begin{array}{c}\text { A.AR(Average } \\
\text { Abnormal Retum) }\end{array}$ & $\begin{array}{l}\text { CAAR(Cotnulative } \\
\text { Average Abnormal } \\
\text { Retum) }\end{array}$ \\
\hline 14 Mei 2019 & t-5 & $-0,0214$ & \\
\hline 15 Mei 2019 & $1-4$ & 0,0038 & $-0,017564355$ \\
\hline $16 \mathrm{Mel} 2019$ & $1-3$ & $-0,0057$ & $-0,0233$ \\
\hline 17 Mè 2019 & $t-2$ & 0,0095 & $-0,0138$ \\
\hline 20 Mei 2019 & $1-1$ & $-0,0044$ & $-0,0182$ \\
\hline 21 Mei 2019 & to & 0.0165 & $-0,0017$ \\
\hline 22 Mei 2019 & $t+1$ & 0,0088 & 0,0071 \\
\hline 23 Mei 2019 & $\mathrm{t}+2$ & 0,0087 & 0,0158 \\
\hline 24 Mei 2019 & $\mathrm{t}+3$ & $-0,0083$ & 0,0074 \\
\hline 27 Mei 2019 & $\mathrm{t}+4$ & 0,0169 & 0,0244 \\
\hline $28 \mathrm{Mei} 2019$ & $t+5$ & 0.0035 & 0,0279 \\
\hline
\end{tabular}

Dari table 4 dapat dilihat Average Abnormal Return periode sebelum sampai sesudah pengumuman hasil pemilihan presiden Indonesia. Dari hasil yang diperoleh average abnormal return sebagian besar menunjukkan hasil Positif artinya saham dari perusahaan Bakal Calon masih bereaksi atau investror masih tertarik berinvestasi pada perusahaan bakal calon tersebut.

Dari table 4 dapat dilihat bahwa CAAR menghasilkan nilai Positif, 
mengidentifikasikan bahwa investor bereaksi positif terhadap pengumuman Hasil Pilpres tetapi mengalami penurunan nilai CAAR setelah pengumuman hasil Pilpres dengan pengumuman Pencalonan. Disaat Pengumuman bakal calon nilainya 0,0490 sedangkan disaat pengumuman Pilpres 0,0279. Artinya mengalami penurunan minat beli investor terhadap saham CEO yang menjadi bakal calon karna kandungan informasi bahwa CEO tersebut kalah dalam pemilihan.

\section{SIMPULAN DAN SARAN}

\section{Simpulan}

1. Berdasarkan hasil dan pembahasan yang penulis uraikan pengaruh pengumuman CEO Bukan Bakal Calon wakil Presiden Indonesia dan Pengumuman Hasil Pilpres 2019 terhadap Return saham maka dapat disimpulkan bahwa Nilai Abnormal Return disaat Pencalonan dan setelah pengumuman Pilpres sama sama mengalami kenaikan dihari setelah terjadinya Peristiwa, untuk nilai Average Abnormal Return juga rata rata memiliki nilai positif artinya saham perusahaan yang dimiliki oleh CEO bakal Calon ini masih dilirik oleh Investor ketika dia menjadi Calon karna degan harapan bisa menang.

2. Untuk nilai Comulatif Abnormal return disaat menjadi bakal calon lebih tinggi daripada disaat pengumuan hasil Pilpres, ini menunjukan bahwa disaat menjadi Bakal calon Investor tertarik karna adanya kandungan informasi pencalonan sedangkan disaat setelah pengumuman Investor sudah mulai ragu untuk berinvestasi diperusahaan bakal calon, ini karna informasi yang menunjukan bahwa Cawapres pemilik Perusahaan ini kalah dan membuat invesor tidak yakin untuk berinvestasi diperusahaanya.dari kesipulan ini dapat dilihat juga bahwa peristiwa politik berpengaruh terhadap return saham.

\section{Saran}

Bagi para investor diharapkan dapat menjadikan penelitian ini sebagai acuan untuk memperhatikan variabel-variabel yang secara signifikan berpengaruh terhadap return saham sebagai pertimbangan untuk berinvestasi di perusahaan yang dimilki oleh bakal calon wakil presiden. Dan jangan langsung menjual saham pahami kondisi dan keadaan pasar baru lakukan penjualan.

Bagi peneliti yang ingin melakukan penelitian selanjutnya agar bisa menambah teori atau menggunakan analisis yang lain untuk menguji pengaruh Pengumuman CEO bakal calon dan bukan Bakal calon wakil presiden Indonesia, dan bisa juga melakukan penelitian lanjutan setelah hasil Pemilu 2019 mendatang dan menjadikan penelitian ini sebagai acuan awal.

\section{DAFTAR PUSTAKA}

Bahtera N F .(2017). Analisis Reaksi Pasar Terhadap Pengumuman Pergantian CEO. The Indonesia Journal of Applied Business: Vol 1 No 1 hal 14-29. https://media.neliti.com

Darmadji dan Fakhrudin .(2012). Pasar Modal di Indonesia (Edisi Tiga).Jakarta : Salemba Empat

Diniar Ayudia Hanung \& Kiryanto,(2015) Analisis Dampak Pemilu Presiden Jokowi terhadap Return Saham. Jurnal Akuntansi Indonesia, Vol. 4 No 2 hal 97-108 http://jurnal.unissula.ac.id

Hartono, Jogiyanto. 2017. Teori Portofolio dan Analisis Investasi. Edisi Kesebelas. 
Yogyakarta : BPFE

Jenter, Dirk dan Fadi Kanaan. 2006. CEO Turnover and Relative Performance Evaluation. Available, http : //www.ssrn.com

Kang, Jun-Koo dan Anil Shivdasani. 1996. Does the Japanese Governance System Enhance Shareholder Wealth? Evidence from Stock Price Effects of Top Management Turnover. The Review of Financial Studies 9 (Winter):1061-1095.

Katti Siti W. (2018). Pengaruh Peristiwa Politik ( Pemilu Presiden dan Pengumuman Susunan Kabinet) Terhadap saham sector industry di bursa efek Indonesia.CAPITAL, Volume 1 No 2 126-133. http://e-jurnal.unipma.ac.id

Lako, Andreas. 2003. Market Reaction to Financial Statement Announcement With and Without confounding Effect. An Empirical Evidence from Jakarta Stock Exchange. The Journal of Accounting, Management, and Economic Research: Vol. 3 No.1, February 2003: 19-33

Neumann, Robert and Torben Voetmenn. 1999. CEO Turnovers and Corporate Governance: Evidence from the Copenhagen Stock Exchange. Article presented at the 26th Annual Meeting of the European Finance Association: August 25-28

Nindita Desiantari ,Yoanna.2009. Reaksi Pasar Terhadap Pengumuman Pergantian CEO diukur dengan Variabilitas Return Saham, Skripsi, Fakultas Ekonomi Universitas Sebelas Maret Surakarta.

Ni Wayan Kustami dan Bradi Rikumahu .2015. Pengaruh CEO Turnover Effect on Stock Company Return That Was Inside Index LQ45 Periode 2007-2012 e-Proceeding Of Management Vol.2, No.1 April 2015 page 596

Pourciau, Susan. 1993. Earnings Management and nonroutine executive changes.Journal of Accounting and Economics 16: 317-336.

Samsul, Mohamad. (2006). Pasar Modal dan Manajemen Portofolio. Jakarta: Erlangga

Sarwoko, Endi dan Islami, Lia Nur Reaksi Pasar Modal Indonesia Terhadap Pergantian Menteri Keuangan (event study saham yang terdaftar di BEI). Jurnal Akuntansi Fakultas Ekonomi Universitas Kanjuruhan Malang Volume 8, Nomor 1, Februari 2012

Sekaran, Uma. 2006. Research Methodss for Busines. Edisi Keempat. Jakarta:Salemba Empat.

Setiawan, Doddy. 2007. Variabilitas Return Saham di Sekitar Pengumuman Pergantian Chief Executive Officer. Jurnal Ekonomi dan Bisnis Indonesia 22, 2 : 180-196.

Santoso Tri Hananto. 2008. An Analysis of Market Reaction To Chief Executive Turnover Announcement : Trading Volume Activity Approach.Presented at the 1st Parahyangan International Accounting and Business Conference Bandung : 13 February 2008.

Tandelilin, Eduardus. 2001. Analisis Investasi dan Manajemen Portofolio. Edisi Pertama. Yogyakarta : BPFE

Tandelilin, Eduardus. (2010). Portofolio \& Investasi Teori dan Aplikasi. (Edisi Pertama).Jogkajarta :Kanisius.

Warner, Jerold B, Ross L. Watts dan Karen H. Wruck. 1988. Stock Prices and Top Management Changes. Journal of Financial Economics 29:461-492.

Weisbach, Michael S. 1988. Outside Directors and CEO Turnover. Journal of Financial Economics 29:431-460

www.yahoofinance.co.id

www.idx.co.id

www.britama.com 